\title{
Correction to: 4D-cubic lattice of chemical elements
}

\author{
Haresh Lalvani ${ }^{1,2}$ \\ Published online: 24 January 2020 \\ (c) Springer Nature B.V. 2020
}

\section{Correction to: Foundations of Chemistry https://doi.org/10.1007/s10698-019-09350-7}

In the original publication of the article under the Acknowledgements section, a contributor name was missed out. The corrected statement should read as follows.

Acknowledgements Thanks to Istvan Hargittai for his feedback and guidance, Egon Schulte for reviewing the 4D topology aspects, Hideto Enyo for his insightful remarks and discussion on isotopes, Shiv Khanna for relation between spin and periodic table and Cristobal Correa on relationship of zero-cyclic sum to architectural structures. Thanks to Eric Scerri for his support through the process, reviewing the animations and offering constructive suggestions and citations. At Pratt Institute, personal thanks to Kirk Pillow, Thomas Hanrahan, Harriet Harris, Allison Druin and Erika Hinrichs. At Lalvani Studio, thanks for digital modeling, visualization and animation support provided by Robinson Strong, Kalliopi Oikonomou, Sharvari Mhatre, Ahmad Tabbakh, Mari Kroin and Mathew Malcom based on author's concepts and recent digital models.

Publisher's Note Springer Nature remains neutral with regard to jurisdictional claims in published maps and institutional affiliations.

The original article can be found online at https://doi.org/10.1007/s10698-019-09350-7.

Haresh Lalvani

hlalvani@pratt.edu; hlalvani@gmail.com

1 Center for Experimental Structures, School of Architecture, Pratt Institute, Brooklyn, NY 11205, USA

2 Lalvani Studio, 164 Bank Street, \#2B, New York, NY 10014, USA 